\title{
Epistemological base of traditional herbal medicine: A case of Uganda
}

\section{Disan Kutesa}

\author{
Makerere University, Uganda.
}

Accepted 11 April, 2014

\begin{abstract}
There is noticeable reversion of traditional approaches in the treatment of physical and psychosocial ailments. In part this comes because conventional medicines are becoming ineffective and expensive and there is a feeling that traditional medical approaches are more, this is coupled by the fact that western medicines are extracted from traditional approaches. The study tried to find out exactly the epistemological foundation of traditional herbals among traditional experts. The rational under guarding this research was that traditional approaches are not exactly the same as western approaches and in many instances, the practitioners are not aware of their methodologies, yet there is no way in post modernism where people can sustain a practice without a clear understanding of its verisimilitude, hence this study was an investigation of the epistemological foundation of traditional herbal medicine. The research was conducted in Central, Western, Northern and Eastern regions of Uganda and principally used document analysis, elite interviews and focus group discussions. In each of the four regions, five traditional birth attendant, five traditional bone setters, five traditional herbalists, five Village elders, and two NACOTHA (National council of traditional healers' association) officials were purposely selected giving a total of eighty eight participants. Data was analyzed using emerging themes, cross case analysis and within case analysis were done in order to obtain the epistemological base of traditional herbal medicine in Uganda. The study concluded that the originative epistemic medium for African traditional herbals are non-conventional, involving Intuition and Conjectures and refutations always facilitated by plant communication, however, testimonial, perceptual and memorial seemings are secondary sources. In addition, their epistemological theory is twofold that is, Malebranche's theory and bucket theory of mind. The study recommended that Bayesian epistemology (experimentation and verification) and Popperian world three of knowledge be introduced in traditional herbal practice.
\end{abstract}

Keywords: Epistemology, foundation, traditional, medicine, herbalism.

E-mail: disankutesa@yahoo.com.

\section{INTRODUCTION}

Among the major philosophical problems that are of supreme importance is Epistemology, the theory of knowledge (http://www.slideshare.net/ncjopson/epistemology). The search for knowledge is inherent in man, what separates man from other animals who are also believed to have intelligence is self-reflection which includes curiosity to discover both the self and that beyond the self, this occurs in epistemological paradigm. Generally, the main concern of Philosophy is the search for the truth (Koestler, 1956), implying that it is not modern Philosophy to speak of knowledge in absolute terms, man's search for knowledge is a perennial task because everything people philosophize; depends on knowledge.

When a speculative philosophical mode is employed, a conclusion can be made that people in all continents have used indigenous plants for treatment of diseases since pre-historic times; a case in point is Socrates who is believed to have taken herbs and died (http://nd/Plato/bloch.htm). In addition, medicinal herbs were found in the personal effect of an Iceman whose body was frozen in the Swiss Alps for more than 5300 years (Castteman, 2001), therefore the utilization of plants as 
therapeutic medicine is an ancient tradition far older than the contemporary science of medicine (Mbewo, 2008).

Generally, the introduction of Euro-Christian philosophical tradition in Africa brought in western scientific paradigm and its consequent disintegrative epistemology, this disintegrative tendency of western epistemology relegates traditional medicine to a position of benign dogma (Anyanwa, 1984). However, today in Uganda the trend is going backward to indigenous medicine; many traditional medical practitioners are becoming famous out of their unwritten herbal epistemic foundation, and documental evidence indicates that $80 \%$ of African populations today use herbals (http://curiosity.discovery.corn/questiona/herbal-remedyusage). However if critical analysis is carried out there is no relative documentation established regarding epistemic theories, and sources of herbal medicine, so this epistemological inquiry was timely.

\section{Statement of the problem}

Traditional herbal medicine is developed using larmarkinism, deontological justification and dyadic truth predicate, it is accepted and respected worldwide alongside western medicine (Ojango, 1981). Traditional herbals do not go through the rigorous testing and experimentation that are normally accorded to western medicine, therefore all categories of traditional medical practitioners have organismic and subjective knowledge, moreover in the first world of knowledge. Contrary, western medicine is objective knowledge, procedural, adversarial, moreover in the third world of knowledge according to Popper (1960).

In addition, western machine is discovered by scientific method and does not progress via a linear accumulation of new knowledge but undergoes periodic revolutions called paradigm shifts. This method consists of essentially three districts steps thus, observation, hypothesis and verification by fresh observation and experiment (Bacon, 1960). Therefore, western medicine has epistemic privilege with a known explicundum and higher verisimilitude than traditional herbals which are justified by doxastic basically.

Thus, the principal question this study addressed was: Why is traditional herbal medicine accepted yet its epistemological base is not known and documented? The dialectical interplay between the flux of ontological dialectics and the demand for axiological peace for both traditional herbalism and western medicine perpetuated this study.

\section{EPISTEMIC THEORY OF TRADITIONAL HERBALS IN UGANDA}

All traditional experts interviewed reported to have used
Malebranche's theory as their epistemic theory. They asserted that God, gods, spirits, ancestors and supernatural forces are responsible for herbal knowledge acquisition. Many traditional experts sacrifice animals, chicken and some provide alcohol in order to appease the gods and spirits to guide them in herbal knowledge acquisition process. One traditional expert had this to say:

"Before my mother died, she spit in my hands and gave me power to attend to pregnant women and I always call her name when I am in the field harvesting herbs".

Another traditional expert reported that when he is possessed by the spirit called "Kalondoozi", he goes to the field to pick herbs, "Kalondoozi" is a spirit he inherited from his father. In addition, one traditional bone setter clearly said that traditional bone setting is a family job, it is hereditary, his father was a famous traditional bone setter in western Uganda and he chose him before his death thus introduced him to bone setting.

A herbalist, moreover a priest, reported that God created plants for their medicinal use, and he believes that administration of medicine is human but healing is divine, interestingly many herbalists have stalls named 'God is able' implying that God has had a hand in their knowledge acquisition. Admittedly, reference to gods, spirits and ancestors is assumed to play a significant role in mitigating the harshness of metaphysical dialectics regarding the axiological stability of society in Uganda. The western epistemological theory which can best explain how traditional healers acquire herbal knowledge is Malebranche's theory, Malebranche was a catholic priest who urged that God puts knowledge in the mind of man; whatever you know, you are reading the divine mind of God.

The fallacy of appealing to supernatural in herbal knowledge acquisition is common in African epistemology, where the subject and object are so fused in their existential prediction to correspond to pantheism, this is a contemporary mystic. The immediate and mediate experiences of traditional experts is usually characterized by a set of contradictions, that is, one and many, individuality and universality, freedom and necessity, reason and sentiments, implying that as propaedeutic to their ontology, traditional experts adhere to cosmology which determines their epistemology but this is illogical, there should be a simultaneous mutual interaction between the self and the cosmology because by nature all theories are conjectures and inherently fallible (Reiser, 1971).

This clearly shows that the current state of traditional herbalism in Uganda is not a rigorous philosophical endeavor, the reference of the transcendental has a disadvantage, as such epistemology has the inherent weakness of surrendering easily to the divine wish, the 
Table 1. Traditional experts source of knowledge.

\begin{tabular}{lc}
\hline Source & Percentage (\%) \\
\hline God, gods, spirits, ancestors/Aha effect (Intuition) & 52 \\
Parents, relatives, indisputable authority (Testimonial, memorial and perceptual seemings) & 41 \\
Plant communication (Conjectures and refutations) & 07 \\
\hline
\end{tabular}

ardours task of logically unraveling the complex and difficult human problem.

It was however found out that all traditional medical experts in Uganda come from families where herbalism is famous, implying that they were born in a "laboratory", grew up in a "laboratory" and acquired herbal knowledge, hence what they call knowledge from gods, ancestors and spirits, is partly their experience (bucket theory of mind), coupled with their mental advantage or Eureka effect, therefore their epistemic theory is twofold, involving Malebranche's theory and bucket theory of knowledge, bucket theory of mind is the lower level of empiricism, a theory responsible for production of western medicine, thus empiricism involves perception and observation but bucket theory of mind has only the element of perception, it has a very low verisimilitude, therefore traditional experts can stumble to truth.

\section{EPISTEMIC SOURCE OF TRADITIONAL HERBALS IN UGANDA}

A total of 88 traditional experts interviewed gave the following responses in relation to epistemic sources of herbal medicine in Uganda (Table 1).

$52 \%$ of traditional experts reported to have acquired knowledge from gods, and spirits. Thus gods guide them when time comes to harvest herbs from the field and its administration to the patients. Many claim to consult mountains, rivers, lakes forests; others claim to read cowrie shells to get herbal knowledge.

It was also found out that many traditional herbalists demand money from patients; mix money with cowrie shells and spread them on a piece of backcloth, the healer later on reads and can prescribe herbal medicine from gods to be administered. A point noted was that reading of cowrie shells in order to acquire herbal knowledge cannot be done by a person who is not possessed by the spirits. Admittedly, belief in gods is not typically an African phenomenon, it was in Greece, Germany and England during the pre-renaissance Europe and when such belief was demolished, development was realized. Such belief in gods as a source of knowledge is a worldwide development phase towards intellectual development. The mythical beliefs in gods as source of knowledge is a guarantee of the death of a free intellectual spirit making the self a prisoner, where gods take over the direction of human faculties to nowhere, hence establishing an authoritarian arrogant and dogmatic approach.

Undoubtedly, intuitionism is the originative source of herbal medicine in Uganda. African traditional healers are very intuitive, and a point to note is that intuitive knowledge is associated to past experience. All traditional medical doctors in Uganda come from families where herbalism is famous, so they were born in a laboratory, grew up in a laboratory and acquired herbal medical knowledge; hence what they call knowledge from gods and ancestors is intuitive knowledge

The African context where gods and spirits are associated with epistemic acquisition should be demolished in the manner Greeks demolished theirs (Ashby, 1960). This will usher in scientific culture, a condition which can effect development and liberate traditional experts from ontological darkness. The first step towards the liberation of Ugandan traditional experts is to acknowledge the current stagnant status of selftutelage and the urgency to shake off the fellers of mythologies, witchcraft, superstition, gods and magical practices

$41 \%$ of traditional experts reported to have acquired knowledge from parents, relatives and this is memorial, testimonial and perceptual seeming. This explains why most of them are fake (Wasswa 1996), because as Ayer (1956) claims, to know empirical objects may be upheld to reference, to perception, to testimony or historical record or to laws but such backing is not always strong enough for knowledge, one may have a poor memory hence prescribe herbals with adverse effects. Another epistemological puzzle of this epistemic source is how do we tell that a specific herbal knowledge comes from an expert? Someone can take up knowledge without evidential clue. Most traditional doctors have accumulated a long track record that can be taken as a sign of reliability but deductively one's personal experience does not constitute an evidence base, rich enough to justify the attribution of reliability to the totality of testimonial, perceptual or memorial source. Herbal knowledge acquisition process should be based on scientific revolutions, involving a revision to existing scientific belief or practice, where revolutions bring with them an overall increase in puzzle solving power, the number and significance of the puzzles (Kuhn, 1962). The urge for a continuous assessment and reassessment of the known or the unknown calls for the participation of the subject than testimonial, memorial and perceptual seemings, which sources occupy central position in traditional herbalism. 
However, $7 \%$ of traditional experts reported to acquire herbs knowledge from conjectures and refutations majorly facilitated by plant communication. Sometimes when animals fall sick, they are monitored, their feeding movement patterns are also monitored, and the grass eaten is noted and given to self when he falls sick. This is in line with popperian epistemology, that is, knowledge grows through conjectures and refutations (Popper, 1966), and this is one of the originative epistemic sources of herbals in Uganda.

As mentioned in the foregoing, $7 \%$ traditional experts reported that they use conjectures and refutations but this is facilitated by plants, plants communicate physically and chemically to people, for example, Sodom apple because it produces a sticky substance, it is used in treatment of wrarts, Sour soup resembles a human heart, it is used in the treatment of heart diseases, bitter leaves because of sourness they are used to treat malaria and fever, that is, sourness is associated with medicine, juice of sawpalmette looks and smells like urine, and it is used to treat urinary problems. Interestingly, there is scientific evidence that such plants have active compounds; hence they are medicinal (http://www.herbalallus.com/communicating.htm)

Admittedly, plant communication is supported by the doctrine of signatures, a spiritual system of beliefs which holds that God puts plants on earth for their medicinal properties and that people are clued to their actions by their shapes and other properties (Harris, 1970).

Generally, the originative source of valid herbal medicine is also twofold involving intuition and conjectures and refutations always facilitated by plant communication, but the majority use testimonial, perceptual and memorial seemings, these are secondary sources of herbal knowledge from indisputable authorities. (Figure 1).

\section{CONCLUSION}

Traditional medical practitioners in Uganda are intellectual explores, intellectual adventures, cognitive revisionists whose inner gaze is so clean and persuasive that people follow them, they are the sages of community, the so called epistemic authorities. Epistemic authorities in the western world are the doctors, philosophers, historians, scientists and lawyers while in the Eastern world, they are known as the Shamans. In Africa, we have the traditional bone setters, traditional birth attendants, traditional herbalists; their source of herbal knowledge is based on intuition and for them they assume that their knowledge is from gods and ancestors but admittedly it is the aha effect, eureka effect or intuitive knowledge. This conclusion is in agreement with other western philosophers like Aristotle and Bergson Henri, who posited that intuition is the originative source of knowledge (Bergson, 1944).

\section{RECOMMENDATIONS}

This study as the first of its kind in Uganda in relation to epistemological foundation of herbal medicine, provides baseline evidence that herbal medicine is real and efficacious (Broughton, 2001), however $93 \%$ of traditional experts have doxa, implying that epistemological continuum of traditional herbalism calls for serious negotiation in the exchange of philosophical ideas between tradition and modern minds. The following recommendations were made:

1. Bayesian epistemology: The home truth is that traditional herbals are efficacious, plants have active compounds, plant organs and properties which resemble human organs and properties are medicinal but with a low curative elements. The self should always look for such features in plants and harvest them. Nevertheless, the theory of sense perceptual experience employed by most traditional experts should be modified and introduce the element of observation in order to avoid tautology and put it at the level of empiricism which is the acceptable theory in production of Western medicine, this will leave out doxa and put traditional herbalism in third world of knowledge (Popper, 1960). Precisely NCRL should closely monitor all traditional experts.

2. Popperian falsification theory: Popperian epistemology should be introduced in traditional herbalism; this involves modifications of the explicundum as well as the explican. The aim is to eliminate doxastic basicality, epistemic luck and subjective episteme in traditional epistemology. Emphasis generally should be on potential infinity because the past does not mean the future (Figure 2).

As shown in Figure 2, this is the criterion of relative potential satisfactoriness; emphasis for herbal knowledge acquisition theory should be on Conjectural turn, Objective turn, Social turn and Metaphysical turn. Admittedly, there should be falsifiability, refutability and testability in herbal knowledge acquisition process, that is, error elimination (EE) should be done to eliminate epistemic luck in traditional herbalism, theories should be tentative (TT) and this evaluation is critical aimed at acquiring dependable herbals. Confirming evidence should not count except when it is the result of a genuine test of the theory, all TMPs need to know that they do not mould or instruct this world by expressing in it, the state of their mind, nor does it instruct them, they should put herbal knowledge in the third world of Karl Popper (Popper, 1966).

Admittedly, traditional birth attendants, traditional bone setters, traditional herbalists and village elders who use herbs cannot easily be eliminated by the Ugandan government because they are accessible and cheap, they should be taught some basic health science and logic to help them in their operations, their role should be to give first aid to patients and refer them to western 


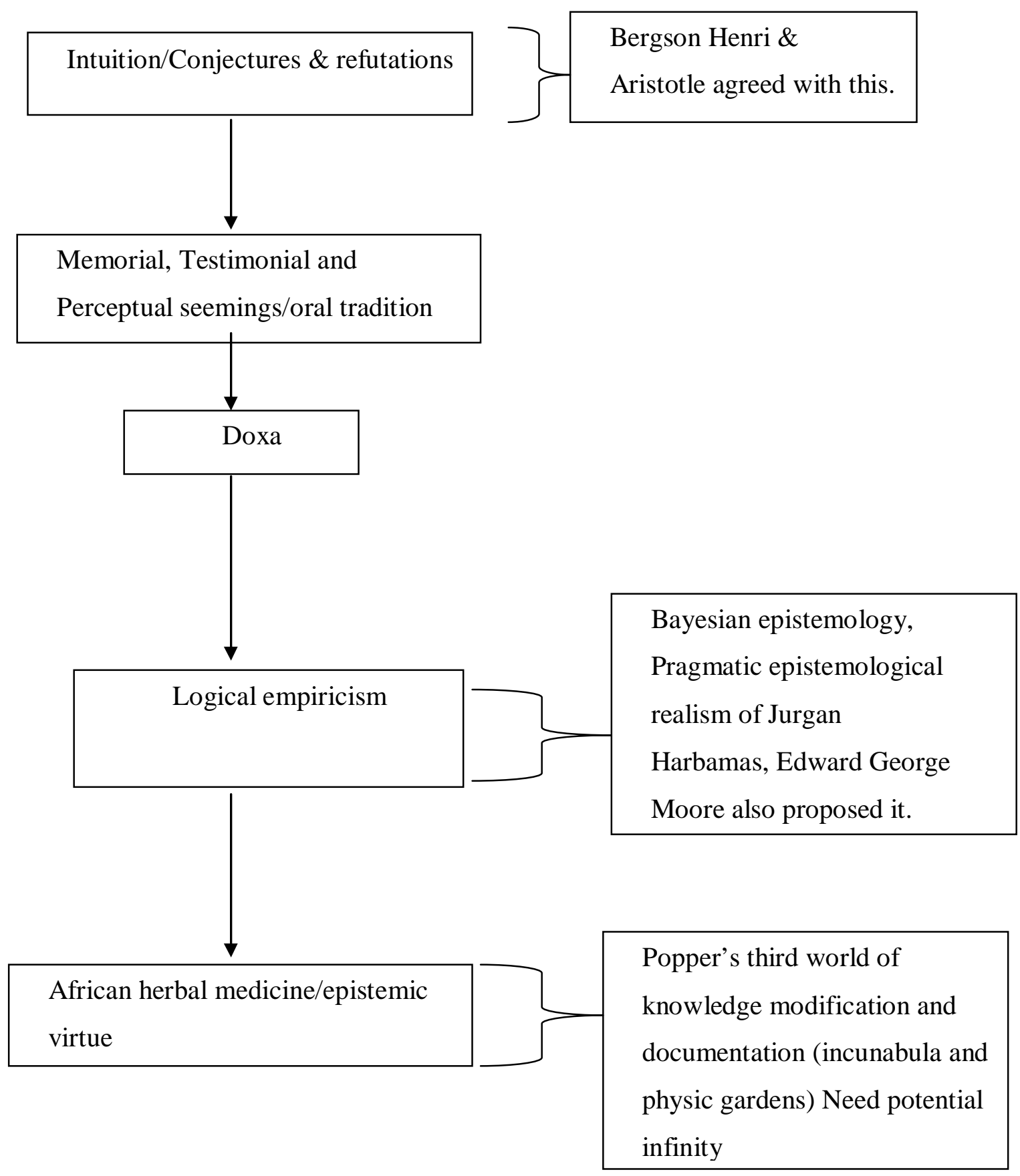

Figure 1. Proposed model of African herbal practice.

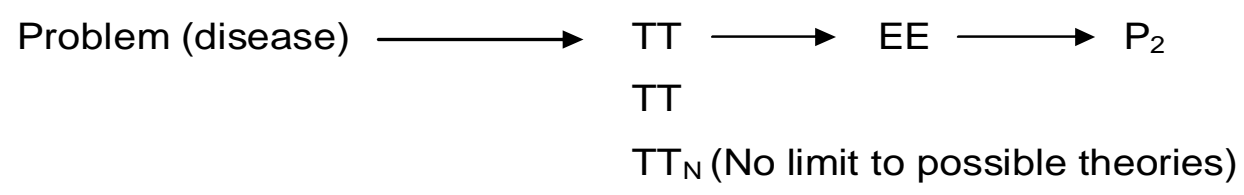

Figure 2. Popperian falsification theory.

doctors, otherwise currently all TMPs lack epistemophilia, have doxa, putting patients in very risky situations.
In contrast, all traditional experts who believe in gods and operate in shrines should be banned from operation, 
their presence is a liability, and many people have lost their lives out of their acts (Wasswa, 2007). Belief in gods stands as the epistome of darkness, lack of consciousness or sense of direction, an indicator that some of the so called traditional experts having reached a sackgasse, dead end, missing links of thought process, they attribute their knowledge to gods, spirits, and unknown forces within the universe. There is need for traditional experts' emancipation from their tutilageunmundigkeit (Kant, 1956), this will be a sure way to liberate traditional doctors from spiritual enslavement, prejudices, idols and avoidable errors.

\section{REFERENCES}

Adler, M. I. (1982). Problems and Possibilities. New York: Macmillan Publishers.

Akumu, E. (1983). The Impact of Christianly on the Acholi Traditional Values and Practices Viewed in the Pastoral Perspective. Unpublished, Gaba Seminary Kampala.

Alexander, T. (1987). John Devey's theory of Art Experiences and Nature. Suny Press.

Amin, M. E. (2005). Social Science Research, Conception, Methodology and Analysis. Kampala Makerere University Printery.

Anderson, H. P., and Chen, X. (1998). Kuhn's theory of scientific revolutions and cognitive psychology. UK: Cambridge University Press.

Armstrong, D. M. (1993). Belief Truth and Knowledge. UK: Cambridge University Press.

Audi, R. (1995). The Cambridge Dictionary of Philosophy. New York: Cambridge University Press.

Austin, J. L. (1970). Philosophical Papers. Oxford, UK: Oxford University Press.

Bergson, H. (1944). Creative Evolution, translated by Arthur Mitchell. New York: Modern Library.

Berkeley, G. (1910). Principles of Human Knowledge. New York.

Berkson, W. K., and Wettersten, J. (1984). Learning from errors Karl Poppers Psychology of learning La Saille. II open court.

Butler, J. D. (1966). Four Philosophies. New York: Harper and Rov.

Chennakesavan, S. (1974). A Critical Study of Hinduism. New York: Asia Publishing House.

Darwin, C. R. (1958). The Origin of Species by Means of Natural Selection. New York: Oxford University Press.

David, N. A. (1977). Buddhism: Its Doctrines and its Methods. New York: St Martin's Press.

Dewey, J. (1934). A Common Faith. Yale University Press.

Edwards, H. (1967). Encyclopedia of philosophy. Vol 2 and 6, New York, Macmillan.

English, P., and Kalumba, K. (1996). Africa Philosophy: A Classical Approach. New Jersey: Prentice Hall.
Feinberg, J. (1973). Social Philosophy. New Jersey: Prentice Hall Inc.

Fung, Y. (1947). The Spirit of Chinese Philosophy. Westport, CT: Greenwood Press.

Gay, L. R. (1996). Educational Research Competencies for Analysis and Application. $5^{\text {th }}$ Edition. New Jersey Prentice hall Inc.

Gettier, E. (1983). Is Justified True Belief Knowledge? Online Text.

Gibb, H. A. R. (1947). Modern Trends in Islam. Chicago: University of Chicago Press.

Greco, J., and Sosa, E. (1999). Guide to Epistemology. Blackwell Publishing Company.

Guignon, C. (1983). Heidegger and the problem of knowledge. Hackett Publishing Company Inc USA.

Hanson, N. R. (1958). Patterns of discovery. Cambridge: Cambridge University Press.

Harris, E. E. (1970). Hypothesis And Perception, George Allen and Unwin, London, Reprinted 2002 Routledge, London.

Harry, A. W. (1983). The Philosophy of Spinoza: Unfolding the lateral processes of his reasoning. Harvard University.

Heidegger, M. (1982). The Basic Problems of Phenomenology. Indian University Press.

Hendricks, V. F. (2006). Mainstream and Formal Epistemology. New York: Cambridge University Press.

Hondrich, T. (1995). The Oxford Companion to Philosophy. New York: Oxford University Press.

Hume, D. (1941). Treatise upon Human Nature. UK: Oxford University Press.

Kannegiesser, H. J. (1977). Knowledge and Science. Macmillan Company of Australia PTY Ltd.

Kant, I. (1956). Critique of Practical reason, Translated by Lewis White Beck. New York: Liberal Arts Press.

Kierkegaard, S. A. (1944). Attack on Christendom, translated by Walter Lowner. Princeton, Princeton University Press.

Klein, P. D. (1981). Certainty: a Refutation of Scepticism. University of Minnesota Press.

Kneller, D. (1989). Critical Theory, Marxism and Modernity. Johns Hopkins University Press.

Kuhn, T. (1962). The Structures of Scientific Revolutions. Chicago: University of Chicago Press.

Citation : Kutesa, D. (2018). Epistemological base of traditional herbal medicine: A case of Uganda. African Educational Research Journal, 6(3): 197-202. 